\title{
Charles Vion d'Alibray, Le Torrismon du Tasse. Tragédie
}

\section{Monica Pavesio}

\section{Q OpenEdition}

1 Journals

\section{Edizione digitale}

URL: https://journals.openedition.org/studifrancesi/21151

DOI: 10.4000/studifrancesi.21151

ISSN: 2421-5856

\section{Editore}

Rosenberg \& Sellier

\section{Edizione cartacea}

Data di pubblicazione: 1 décembre 2019

Paginazione: 567

ISSN: 0039-2944

\section{Notizia bibliografica digitale}

Monica Pavesio, «Charles Vion d'Alibray, Le Torrismon du Tasse. Tragédie», Studi Francesi [Online], 189

(LXIII | III) | 2019, online dal 01 mars 2020, consultato il 11 novembre 2021. URL: http://

journals.openedition.org/studifrancesi/21151 ; DOI: https://doi.org/10.4000/studifrancesi.21151

Questo documento è stato generato automaticamente il 11 novembre 2021.

\section{(c) (i) (9)}

Studi Francesi è distribuita con Licenza Creative Commons Attribuzione - Non commerciale - Non opere derivate 4.0 Internazionale. 


\title{
Charles Vion d'Alibray, Le Torrismon du Tasse. Tragédie
}

\author{
Monica Pavesio
}

\section{NOTIZIA}

Charles Vion d'Alibray, Le Torrismon du Tasse. Tragédie. Edizione, note e introduzione di D. Dalla Valle, Bern, Peter Lang, 2019, 284 pp.

1 L'unica tragedia scritta da Torquato Tasso, Il Re Torrismondo, pubblicata per la prima volta nel 1587 e ristampata numerose volte, ottenne un successo precoce in terra francese: fu infatti tradotta, rappresentata e pubblicata negli anni Trenta del xVII secolo da un illustre italianista, Charles Vion d'Alibray, che quattro anni prima aveva tradotto l'Aminta. La pubblicazione nel 1636 della traduzione di questa tragedia italiana, accompagnata da una lunga prefazione $A u$ Lecteur, è particolarmente importante perché rappresenta un tassello di notevole interesse nel dibattito teorico concernente il conflitto tra il genere tragico e quello tragicomico, che si stava elaborando in quegli anni in Francia.

Dopo aver dedicato alla tragedia di Vion d'Alibray e alla sua prefazione alcuni articoli, Daniela Dalla Valle ci offre l'edizione critica del testo di Vion, facendola precedere da uno studio approfondito sulle quarantaquattro pagine di testi teorici o collaterali alla tragedia (Préface, Argument, interventi attuati per la messa in scena al teatro del Marais, lista degli errori fatti a stampa, privilège) e sulla traduzione, confrontandola con la prefazione ed inserendola nel dibattito teorico di quegli anni. Per favorire il confronto con il testo tassiano, Dalla Valle fornisce in appendice il testo del Re Torrismondo del Tasso, nell'edizione moderna di B.T. Sozzi e M. Guglielminetti, e fa precedere ogni battuta del testo francese dalla segnalazione dei versi corrispondenti italiani, segnalando le soppressioni e le modifiche attuate da Vion d'Alibray. Aggiunge, sempre in appendice, l'advertissement della pastorale La pompe funebre, ou Damon et Cloris, 
traduzione de Le pompe funebri di Cesare Cremonini, pubblicata da Vion d'Alibray nel 1634, due anni prima del Torrismon.

3 Il drammaturgo francese manifesta un'adorazione per il Tasso, che reputa ancora un modello esemplare, ma nello stesso tempo vuole scrivere un testo rappresentabile sulle scene francesi degli anni Trenta e adeguarlo a una delle leggi formulate durante $\mathrm{i}$ dibattiti di quegli anni, ossia la prevalenza dell'azione sul racconto. Vion interviene, quindi, con importati note al testo, che Daniela Dalla Valle segnala a fondo pagina, sottolineando l'interesse del traduttore francese per la rappresentazione della tragedia tassiana.

Un'edizione critica frutto di un lavoro accuratissimo, che presenta, per la prima volta insieme, il testo di partenza del Tasso e il testo di arrivo di Vion, accompagnati dai paratesti e dalle note dell'autore, ampiamente analizzate e commentate. Completano il volume una bibliografia e un indice dei nomi. 